\title{
Aminopropyltriethoxysilane functionalized MCM-41 and SBA-15 nanostructured materials for carbon dioxide adsorption
}

\author{
Marcela Nascimento Barbosa ${ }^{1}$, Maria José Fonseca Costa ${ }^{1}$, \\ Maricele Nascimento Barbosa ${ }^{2}$, Valter José Fernandes Júnior ${ }^{1}$, \\ Giancarlo Richard Salazar-Banda ${ }^{3,4}$, Álvaro Reyes-Carmona ${ }^{5}$, \\ Enrique Rodríguez-Castellón ${ }^{5}$, Antonio Souza Araujo ${ }^{1}$
}

\footnotetext{
${ }^{1}$ Federal University of Rio Grande do Norte, Institute of Chemistry, Campus Universitário Lagoa Nova, CEP: 59078970, Rio Grande do Norte, Natal, Brazil.

${ }^{2}$ Federal University of Rio Grande do Norte, Department of Physiology, Campus Universitário Lagoa Nova, CEP: 59078-970, Rio Grande do Norte, Natal, Brazil.

${ }^{3}$ Instituto de Tecnologia e Pesquisa, Laboratório de Eletroquímica e Nanotecnologia (LEN), Avenida Murilo Dantas 300, CEP: 49032-490, Sergipe, Aracaju, Brazil.

${ }^{4}$ Universidade Tiradentes, Programa de Pós-graduação em Engenharia de Processos (PEP), Avenida Murilo Dantas 300, CEP: 49032-490, Sergipe, Aracaju, Brazil

${ }^{5}$ University of Málaga, Faculty of Sciences, Department of Inorganic Chemistry, Crystallography and Mineralogy, Av. Cervantes 2, CP. 29071, Malaga, Spain.

e-mail: marcelaufrn.quimica@gmail.com, mariadedeia@hotmail.com, valter.ufrn@gmail.com, araujo.ufrn@gmail.com, maricelebarbosa@yahoo.com.br, gianrsb@gmail.com, alvarorcarmona@gmail.com, castellon@uma.es
}

\begin{abstract}
The design of effective $\mathrm{CO}_{2}$ capture materials is a current challenge. Here, we report the synthesis of aminosilanes-functionalized MCM-41 and SBA-15 materials with high efficiency toward carbon dioxide adsorption. The functionalization of the mesoporous silicas involves a post-synthesis method by impregnation with 3-aminopropyltriethoxysilane. The carbon dioxide adsorption capacities for the samples were carried out under ambient pressures. The results evidenced that aminosilanes with a terminal amine were functionalized through covalent coupling of this group onto the channels' surface in the ordered mesoporous silica. It means that the amine is anchored on the surface of the largest pores of the MCM-41 and SBA-15 supports. The Lagergren kinetic model evidenced the enhanced carbon dioxide adsorption capacity and stability of the functionalized ordered mesoporous molecular sieves.
\end{abstract}

Keywords: 3-Aminopropyltriethoxysilane; Carbon dioxide; Functionalization; MCM-41; SBA-15.

\section{INTRODUCTION}

The increase in atmospheric carbon dioxide concentration is becoming a serious environmental problem. It is well-known that the primary human activity that emits $\mathrm{CO}_{2}$ is the combustion of fossil fuels (coal, natural gas, and oil) for energy and transportation. However, specific industrial processes and land-use changes also emit $\mathrm{CO}_{2}$. In the transition toward a more sustainable energy economy, fossil fuels are likely to remain the primary source of global energy supply for the future [1,2]. Thus, the continuous use of fossil fuels is dependent on the reduction of $\mathrm{CO}_{2}$ emissions. Improving energy utilization efficiency and increasing the use of low-carbon energy sources are potential ways to reduce $\mathrm{CO}_{2}$ emissions. Recently, carbon capture and storage techniques have been proposed as an emerging technology to minimize $\mathrm{CO}_{2}$ emissions effectively [3].

The most common technologies for $\mathrm{CO}_{2}$ scrubbing from power plant flue gas are based on adsorption, using liquid amines. The major drawbacks of these adsorbents are the large amount of energy required for regeneration, equipment corrosion, and solvent degradation in the presence of oxygen [4]. Therefore, extensive efforts have been directed to developing alternative procedures for $\mathrm{CO}_{2}$ capture, such as cryogenic technologies, adsorption, or membrane-based techniques [5,6]. Because of the low energy requirement, the cost 
advantage, and ease of applicability over a relatively wide range of temperatures and pressures, adsorption separation attracts much interest.

The most critical element of chemical adsorption of $\mathrm{CO}_{2}$ involves the design and development of a suitable adsorbent, which consists of porous support onto which an amine is attached [7]. The adsorption of carbon dioxide has been studied in various mesoporous materials, including the MCM-41 and SBA-15 [8-11]. Different research groups have tried to introduce amine groups into mesoporous silicas because of their elevated surface area. Polyethanolamine has been a modifying alternative for MCM-41-type materials, significantly improving amine's efficiency for $\mathrm{CO}_{2}$ adsorption [12]. The use of amino groups anchored onto the support dramatically reduces the potential toxicity of the process, minimizing the corrosion of equipment and simplifying the regeneration step. Mesoporous silicas with different pore sizes were modified by aminosilanes, and $\mathrm{CO}_{2}$ adsorption capacity was improved. However, (3-trimethoxysilylpropyl) diethylenetriamine modified mesoporous silicas with small pores, such as MCM-41 (2.9 or 3.1 nm) and SBA-15 (6.2 or $7.1 \mathrm{~nm}$ ) were significantly decreased at high aminosilane density. In contrast, modified SBA-15 with a large pore $(10.6 \mathrm{~nm})$ exhibited a further improvement of $\mathrm{CO}_{2}$ adsorption capacity and amine efficiency [13-15].

According to Sanz and coworkers [16], mesoporous molecular sieves MCM-41 were modified by impregnation with polyethyleneimine (PEI), and $\mathrm{CO}_{2}$ adsorption properties of these materials depend on the kind and amount of organic compound loaded. Grafted samples showed amine efficiencies in $\mathrm{CO}_{2}$ capture up to $0.38 \mathrm{~mol} \mathrm{CO} / \mathrm{mol} \mathrm{N}$, leading to $\mathrm{CO}_{2}$ uptake values ranging from 0.87 to $1.7 \mathrm{mmol} . \mathrm{g}^{-1} \mathrm{CO}_{2} / \mathrm{g}$ ads ( i.e., from 38.2 to $76.9 \mathrm{mg} \mathrm{CO} / \mathrm{g}$ ads at pure $\mathrm{CO}_{2}, 45^{\circ} \mathrm{C}, 1$ bar) [16]. The critical issue for adsorption separation is to develop an adsorbent with high $\mathrm{CO}_{2}$ adsorption capacity and high $\mathrm{CO}_{2}$ selectivity.

Here, we incorporated aminopropyltriethoxysilane (abbreviated as APTES) into MCM-41 and SBA-15 mesoporous materials to improve their adsorption capacities for $\mathrm{CO}_{2}$ under ambient conditions of temperature and pressure. The developed adsorbents were characterized by X-ray diffraction (XRD), scanning electron microscopy (SEM), transmission electron microscopy (TEM), also equipped by an energy-dispersive Xray spectroscopy detector, nitrogen adsorption-desorption measurements, and X-ray photoelectron spectros-

copy (XPS). The results demonstrated that chemical functionalization had a positive effect on the sorption capacity of the nanostructured materials.

This study also aimed to optimize the synthesis of APTES-functionalized mesoporous materials by preserving the ordered structure while favoring the anchoring of the amine onto the material surface. The optimization is intended to lower costs without jeopardizing performance to make the process scalable. This issue is essential to bring the process to industrial application. A significant portion of the cost structure is related to the structure-directing agent (SDA) - Pluronic. In order to achieve our purpose, variations in the mass ratio of TEOS and the SDA were carried out.

\section{MATERIALS AND METHODS}

\subsection{Synthesis and functionalization of mesoporous materials}

According to studies published elsewhere, ordered mesoporous molecular sieves MCM-41 and SBA-15 were synthesized by a hydrothermal method $[16,17]$. The synthesis by the hydrothermal method was carried out in $200 \mathrm{~mL}$ Teflon containers introduced inside the system (autoclave stainless) under heating at $100{ }^{\circ} \mathrm{C}$. In the synthesis of MCM-41, reagents precursors as silicon dioxide (Sigma-Aldrich) as a silicon source, sodium hydroxide as a sodium source, cetyltrimethylammonium bromide (CTABr) as a template structure, and distilled water as a solvent were used. An initial mixture with $11.68 \mathrm{~g}$ of silicon dioxide, $165 \mathrm{~g}$ of distilled water, and $3.74 \mathrm{~g}$ of sodium hydroxide was stirred for $2 \mathrm{~h}$ at $60{ }^{\circ} \mathrm{C}$, and then it was added to an aqueous solution with $17.11 \mathrm{~g}$ of $\mathrm{CTABr}$ for $30 \mathrm{~min}$ to obtain a homogeneous mixture. After that, this reactive hydrogel was transferred to a Teflon-lined stainless-steel autoclave, which was maintained at $100{ }^{\circ} \mathrm{C}$ for $96 \mathrm{~h}$. A molar composition 1 CTMABr. $2 \mathrm{NaOH} .4 \mathrm{SiO}_{2} .200 \mathrm{H}_{2} \mathrm{O}$ was used. The obtained material was filtered, washed with distilled water, dried at $100{ }^{\circ} \mathrm{C}$ in a drying oven for $4 \mathrm{~h}$, and calcined in $\mathrm{N}_{2}$ and with airflow at $450{ }^{\circ} \mathrm{C}$ for $2 \mathrm{~h}$ for removing the surfactant $[17,18]$.

The hydrogel to obtain the SBA-15 mesoporous molecular sieve was prepared with the following composition in grams: $10.4 \mathrm{TEOS} / 4.8 \mathrm{P} 123 / 10 \mathrm{HCl} / 174 \mathrm{H}_{2} \mathrm{O}$. Previous reports have successfully obtained this material using Pluronic F127 and phenolic resin oligomers as precursors. However, the quantities, in grams, of these reagents were higher than the ones used in this work (i.e., TEOS/SDA ratios of 0.625 [19] and 1.875 [20] versus 2.17 used in this work). In this way, the choice of precursors and their quantities allowed lowering the synthesis cost. The mixture was stirred at $40{ }^{\circ} \mathrm{C}$ for $24 \mathrm{~h}$, and it was transferred to a Teflon-lined 
stainless-steel autoclave, which was kept at $100{ }^{\circ} \mathrm{C}$ for $48 \mathrm{~h}$. The precipitate was filtered, washed with distilled water, and dried at $100{ }^{\circ} \mathrm{C}$ in a drying oven overnight. The dried precipitate was calcined in air at 550 ${ }^{\circ} \mathrm{C}$ for $6 \mathrm{~h}$ to remove the structure-directing agent.

The calcined MCM-41 and SBA-15 materials were functionalized by the post-synthesis method, using a system reflux to impregnate the APTES amine. Initially, the MCM-41 and SBA-15 were previously dried at $100{ }^{\circ} \mathrm{C}$ under $\mathrm{N}_{2}$ flow for $2 \mathrm{~h}$. Afterward, $1 \mathrm{~g}$ of the mesoporous material was added to the mixture containing APTES $(3 \mathrm{~mL})$ and ethanol $(30 \mathrm{~mL})$ and submitted to reflux at $75^{\circ} \mathrm{C}$ for $24 \mathrm{~h}$. Later, the products were filtered and washed several times with ethanol and dried at $100{ }^{\circ} \mathrm{C}$ overnight. The obtained samples were labeled as AMCM-41 and ASBA-15, relative to MCM-41 and SBA-15 after grafting with 3-aminopropyltriethoxysilane.

\subsection{Physicochemical characterization}

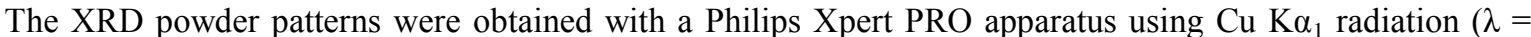
$0.1540 \mathrm{~nm}$ ) with a Ge (111) monochromator working at $45 \mathrm{kV}$ and $35 \mathrm{~mA}$. All the low-angle measurements were made with a step size of 0.02 degrees. The SEM micrographs were obtained using either an XL30ESEM model or JEOL SM 840 microscopes, both working at $20 \mathrm{kV}$. Samples were placed on an aluminum drum and metallized with a gold film using a JEOL Ion Sputter JFC 1100. The TEM images were obtained using a Philips CM 200 microscope working at $100 \mathrm{kV}$. The measurements of energy-dispersive X-ray spectroscopy were registered using an EDAX CM200ST probe based on a SiLi detector. The samples were dispersed in 2-propanol and dropped over a $\mathrm{Cu}$ grid.

Nitrogen adsorption-desorption measurements were performed at liquid $\mathrm{N}_{2}$ temperature $\left(-196{ }^{\circ} \mathrm{C}\right)$ with an ASAP 2020 apparatus from Micromeritics. Before each test, samples were degassed by $12 \mathrm{~h}$ at $150{ }^{\circ} \mathrm{C}$ and $10^{-2} \mathrm{~Pa}$. The specific surface area $\left(\mathrm{S}_{\mathrm{BET}}\right)$ was calculated using the BET method, and the specific pore volume $(\mathrm{Vp})$ was estimated at $\mathrm{P} / \mathrm{P}_{0}=0.98$. The pore size distribution was calculated following the Kruk-JaroniecSayari method [21], taking the desorption branch's data and assuming a cylindrical pore model.

XPS studies were conducted on a Physical Electronic PHI 5700 spectrometer using nonmonochromatic $\mathrm{Mg} \mathrm{K} \alpha$ radiation $(300 \mathrm{~W}, 15 \mathrm{kV}, 1253.6 \mathrm{eV})$. The core level signals of $\mathrm{C} 1 \mathrm{~s}, \mathrm{~N} 1 \mathrm{~s}, \mathrm{O}$ 1s, and Si 2p were analyzed with a hemispherical multichannel detector. The binding energy values were referenced to the $\mathrm{C} 1 \mathrm{~s}$ signal $(284.8 \mathrm{eV})$. Shirley type background and Gauss-Lorentz curves were used to determine the binding energy values for each element.

\subsection{Adsorption of $\mathrm{CO}_{2}$ and kinetics}

The $\mathrm{CO}_{2}$ adsorption tests consisted of two steps: activation and adsorption. A mass sample of approximately $100 \mathrm{mg}$ was transferred to a glass sample holder contained within the reactor and subjected to an activation step into a stream of $\mathrm{N}_{2}$, approximately $150 \mathrm{~mL} \mathrm{~min}^{-1}$ for $2 \mathrm{~h}$ at a temperature of $200{ }^{\circ} \mathrm{C}$. After activation, the system was cooled to room temperature and then performed the adsorption step. Before starting the adsorption, the adsorbent was weighted again. The adsorption was carried out under atmospheric pressure and $\mathrm{CO}_{2}$ flowing at $150 \mathrm{~mL} \mathrm{~min}^{-1}$, at room temperature and variation in reaction time from 0 to $210 \mathrm{~min}$. The adsorption capacity was calculated according to the weight variation observed to reach equilibrium as being equal to the ratio of the amount of $\mathrm{CO}_{2}$ adsorbed by the adsorbent mass activated.

The adsorption kinetics was described by kinetic models of pseudo-first and second-order. The linear form of the models is given by Lagergren Equations (1) and (2) [22, 23].

$$
\begin{aligned}
& \log \left(q_{e}-q_{t}\right)=\log q_{e}-\left(K_{l} / 2.303\right) t \\
& t / q_{t}=1 /\left(K_{2} q_{e}^{2}\right)+\left(1 / q_{e}\right) t
\end{aligned}
$$

The values of $K_{l}$ can be obtained from the slope of the plot of $\log \left(q_{e}-q_{t}\right)$ versus $t$. The plot of $t / q_{t}$ versus $t$ gives a linear relationship, allowing for the computation of $q_{e}$ and $\mathrm{K}_{2}$. The validity can again be tested by comparing the values of $q_{e}$ obtained from both the plots and experimental data [24].

\section{RESULTS AND DISCUSSION}

\subsection{Materials Characterization}

The APTES-functionalized mesoporous molecular sieves MCM-41 and SBA-15, before and after surface modification, were characterized by XRD (Figures 1 and 2). The XRD patterns of MCM-41 (Figure 1a) and 
AMCM-41 (Figure 1b) are consistent with the literature, showing one broad peak corresponding to the plane (100), along with three small peaks of the crystal planes (110), (200) and (210), which are typical features of MCM-41 materials [25, 26].

Similar behavior was observed with SBA-15 and ASBA-15 materials that presented the diffraction peaks characteristic of mesoporous silica in the plans (100), (110), and (200), as shown in Figure 1(c,d), for SBA-15 and ASBA-15, respectively. The structures of mesoporous materials were preserved after functionalization [27, 28].
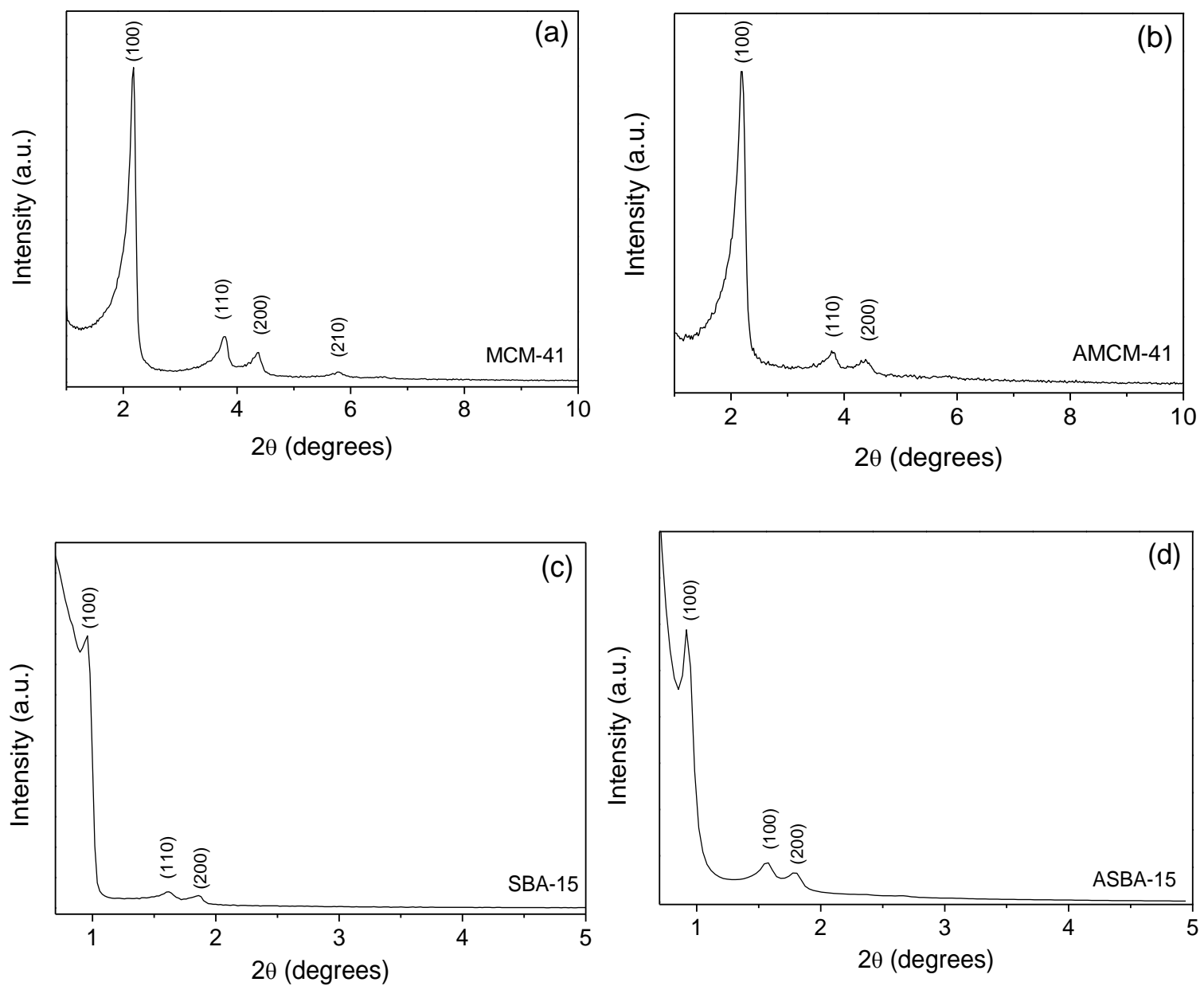

Figure 1: Low-angle XRD diffractograms of the synthesized materials: (a) MCM-41 and (b) AMCM-41 (MCM-41 after grafting with 3-aminopropyl-triethoxysilane), as well as (c) SBA-15 and (d) ASBA-15 (SBA-15 after grafting with 3aminopropyl-triethoxysilane).

Figure 2 shows the SEM micrographs of the synthesized and functionalized samples. This technique was used to observe the morphology of the materials obtained. The synthesized materials are formed by the agglomeration of particles generally rounded. Moreover, for samples AMCM-41 and ASBA-15 (Figure 2b, $2 \mathrm{~d}$ ), particles' morphology is similar to the morphology of the synthesized materials, MCM-41 and SBA-15 (Figure 2a, 2c).

The mesoporous hexagonal structure of these materials is not observed because this technique does not provide an image resolution that reveals visually mesoporous hexagonal channels and their lateral silica tubes. Then, the developed materials were also characterized by TEM. The TEM images of the synthesized MCM-41 and SBA-15 materials, shown in Figure 3, evidence the characteristic structures of mesoporous materials since the formation of the hexagonal ordered mesoporous structure is observed, demonstrating the high-quality material that was obtained. 
Besides the hexagonal mesoporous, we observed silica tubes formed in parallel. This result directly correlates with the XRD data, in which the presence of the diffraction peak related to the plane (100) corresponds to the tubular channels formed by the silica material. The same mesoporous structures were observed for samples functionalized AMCM-41 and ASBA-15 without compromising their structure even after functionalization with the amine. The functionalized materials maintained their hexagonal formation, as well as the ordering of their silica tubes.
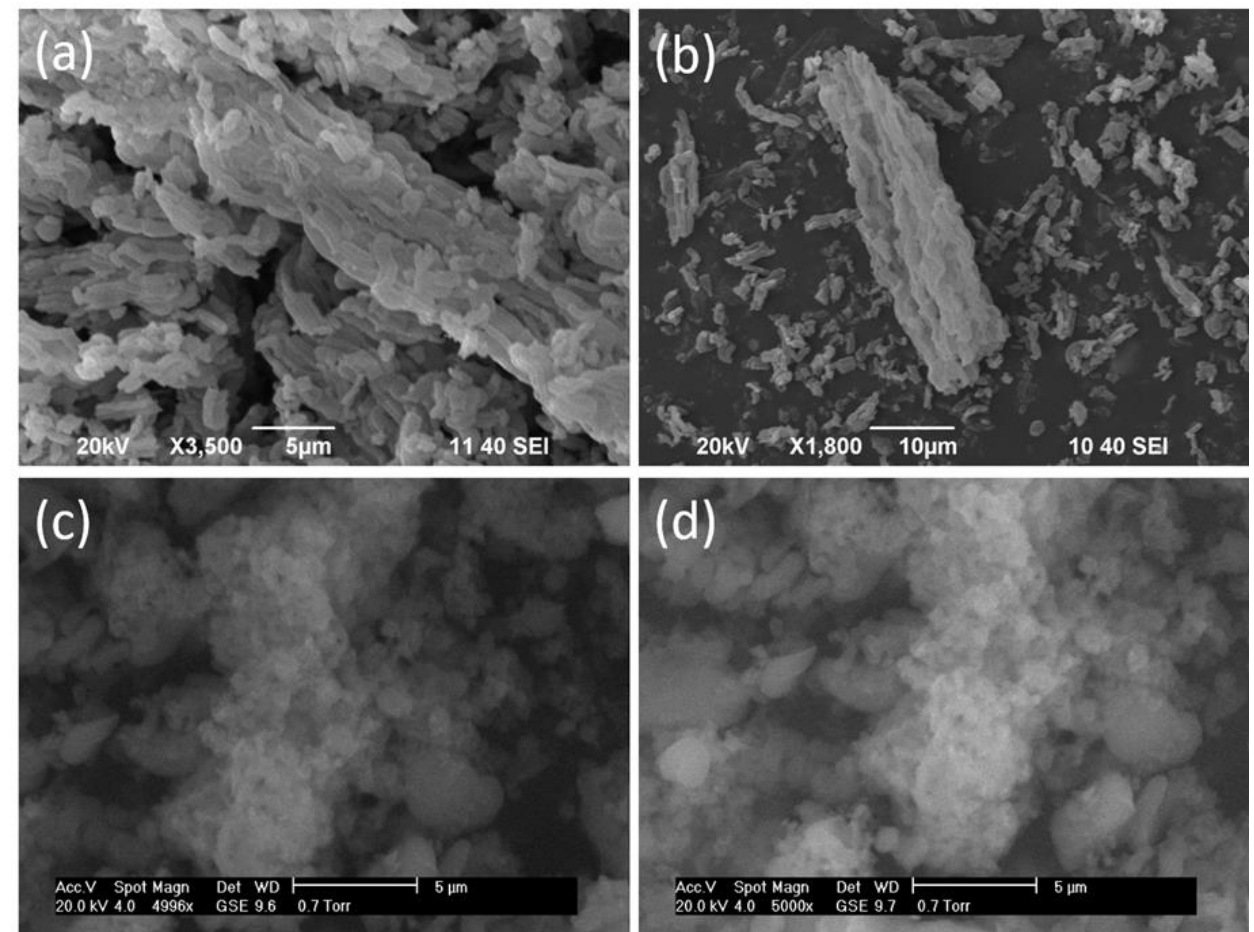

Figure 2: SEM images taken for samples (a) SBA-15, (b) ASBA-15, (c) MCM-41 and (d) AMCM-41.
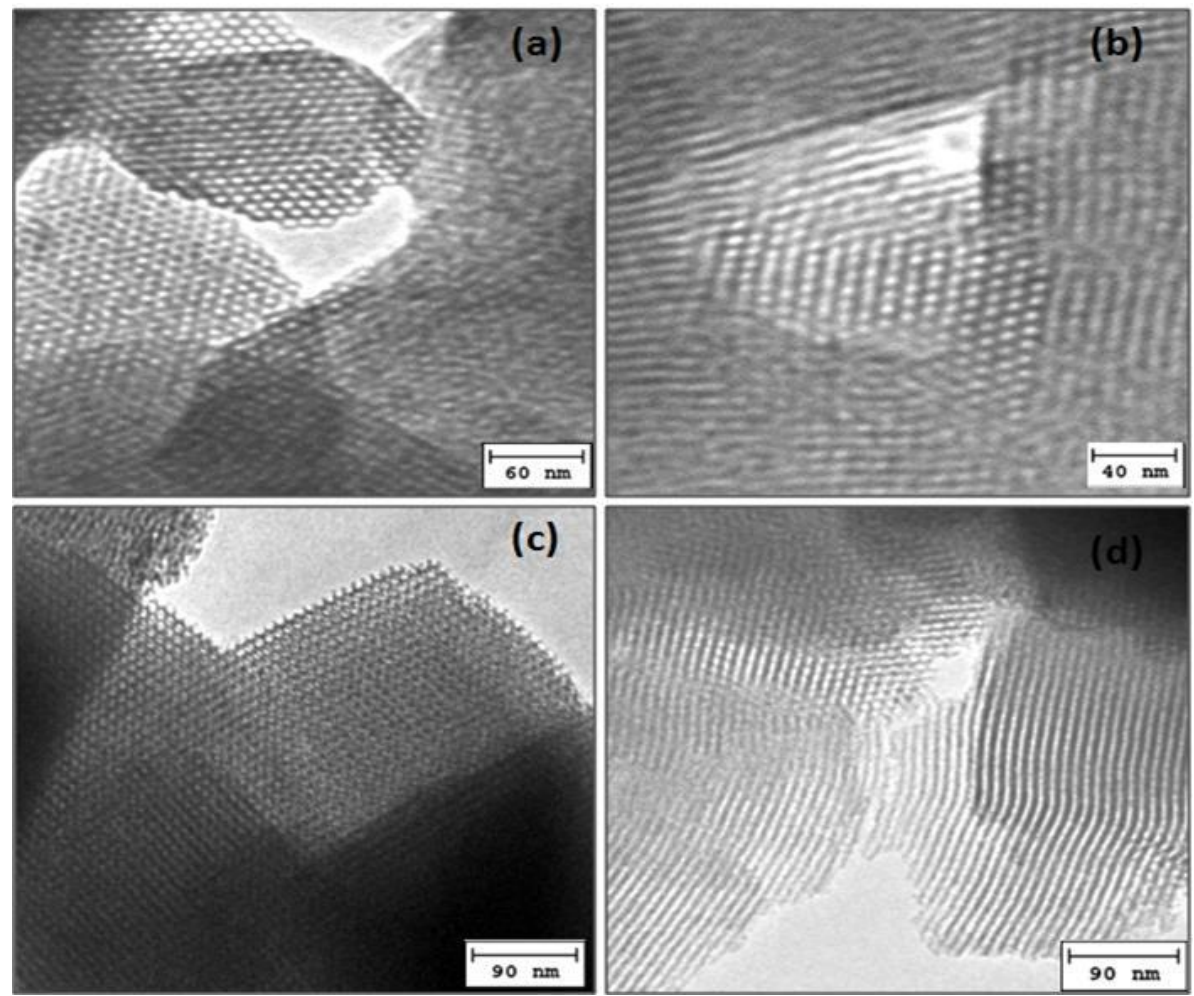

Figure 3: TEM images showing highly-ordered and a long-range hexagonal array of mesopores in the obtained materials before and after modification with aminosilanes: (a) MCM-41, (b) AMCM-41, (c) SBA-15, and (d) ASBA-15. 
Figure 4 shows the nitrogen adsorption/desorption isotherms of the materials studied. All samples have the type-IV isotherm, according to the IUPAC [29], characteristic of mesoporous materials. Precisely, The SBA-15-based materials are Type IV(a) since the adsorption and desorption branches do not fully match, and the MCM-41-based materials are Type IV(b), with fully matched adsorption-desorption. Moreover, the SBA15 displays an $\mathrm{H} 1$ hysteresis loop [30, 31], which changes to H2(a) upon the incorporation of the amine [29]. $\mathrm{H} 1$ hysteresis is characteristic of mesoporous materials with uniform cylindrical pores, while $\mathrm{H} 2$ (a) can be attributed to pore-blocking or narrowing of pore necks [29]. The change in the hysteresis loop is expected because the amine is occupying the pores. The isotherms of the samples have a sharp capillary condensation step, indicating uniform pores. The adsorption and structural parameters of the porous materials are summarized in Table 1.

Table 1: Textural properties of the obtained materials before and after surface modification with aminosilanes.

\begin{tabular}{c|c|c|c|c|c}
\hline MATERIALS & $\mathrm{a}_{\mathbf{0}}(\mathbf{n m})$ & $\mathbf{D p}(\mathbf{n m})$ & $\mathbf{W t}(\mathbf{n m})$ & $\mathbf{V p}\left(\mathbf{c m}^{3} \mathbf{g}^{-1}\right)$ & $\mathbf{S}_{\text {BET }}\left(\mathbf{m}^{2} \mathbf{g}^{-1}\right)$ \\
\hline MCM-41 & 4.85 & 2.80 & 2.00 & 0.81 & 1070 \\
\hline SBA-15 & 12.43 & 6.40 & 6.30 & 1.08 & 715 \\
\hline AMCM-41 & 4.63 & 1.90 & 2.70 & 0.43 & 665 \\
\hline ASBA-15 & 11.10 & 4.30 & 6.80 & 0.76 & 465 \\
\hline
\end{tabular}

$\mathrm{a}_{0}$ : Lattice spacing [32]; Dp: pore diameter; Wt: wall thickness $\left(\mathrm{Wt}=\mathrm{a}_{0}-\mathrm{Dp}\right)$; Vp: pore volume; $\mathrm{S}_{\mathrm{BET}}$ : surface area

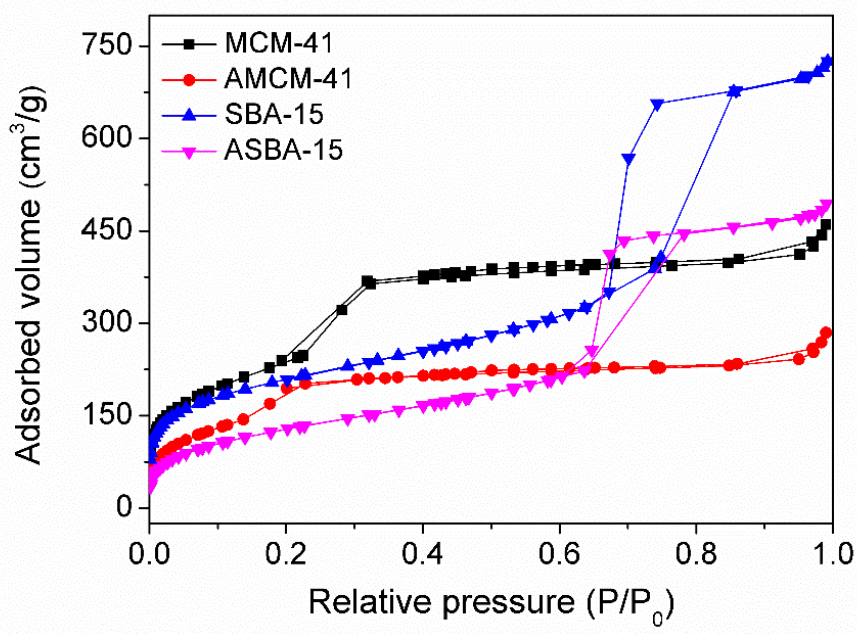

Figure 4: Nitrogen adsorption and desorption isotherms at $-196^{\circ} \mathrm{C}$ for the MCM-41, AMCM-41, SBA-15, and ASBA-15 materials.

The MCM-41 and SBA-15 samples exhibit high surface area values $\left(\mathrm{S}_{\mathrm{BET}}\right)$, which are equivalent to 1070 and $713 \mathrm{~m}^{2} \cdot \mathrm{g}^{-1}$, respectively. Expectedly, the functionalized samples, AMCM-41 and ASBA-15, have lower values regarding their textural properties compared with the parent materials, with surface areas of 665 and $465 \mathrm{~m}^{2} \cdot \mathrm{g}^{-1}$, respectively. This outcome occurs because the amines are filling up the porous structure, which is responsible for the large specific surface areas. This reduction in the surface area is ratified by the reduction in pore sizes and $\mathrm{a}_{0}$ upon functionalization, as shown in Table 1.

The results concerning the characterization by XPS of the synthesized mesoporous materials are given in Table 2. The nitrogen concentration is higher for both functionalized samples than for the nonfunctionalized samples since those latter do not have nitrogen in their composition. The values for $\mathrm{N}$ and $\mathrm{C}$ observed in MCM-41 and SBA-15 come from impurities rather than amines. It is because significant differences were observed in these values when compared to AMCM-14 and ASBA-15. Therefore, these differences in the $\mathrm{N}$ content in the non-functionalized and functionalized samples evidence the presence of amine groups in these materials. 
Table 2: Atomic concentrations of the elements in the synthesized materials determined by XPS measurements.

\begin{tabular}{c|c|c|c|c|c|c}
\hline MATERIALS & $\mathbf{C} 1 \mathbf{s}$ & $\mathbf{N} 1 \mathbf{s}$ & $\mathbf{0 1 s}$ & $\mathbf{S i} \mathbf{2 p}$ & $\mathbf{C}_{\mathbf{p}} \mathbf{C}_{\mathrm{a}} / \mathbf{N}$ & $\mathbf{0} / \mathbf{S i}$ \\
\hline MCM-41 & 4.95 & 0.18 & 64.1 & 30.8 & - & 2.08 \\
AMCM-41 & 17.3 & 2.25 & 53.4 & 27.0 & 5.49 & 1.97 \\
SBA-15 & 5.62 & 0.16 & 63.2 & 31.1 & - & 2.03 \\
ASBA-15 & 15.6 & 2.52 & 53.5 & 28.3 & 3.96 & 1.88 \\
\hline
\end{tabular}

Figure 5 shows the N $1 s$ core-level spectra for the APTES-functionalized samples, AMCM-41 and ASBA-15. These spectra can be decomposed into two contributions. The most intense peak at $399.4 \mathrm{eV}$ is assigned to amine groups, and the second one, with lower relative intensity at $401.5 \mathrm{eV}$, is due to the protonated amine being more pronounced for the ASBA-15 sample.
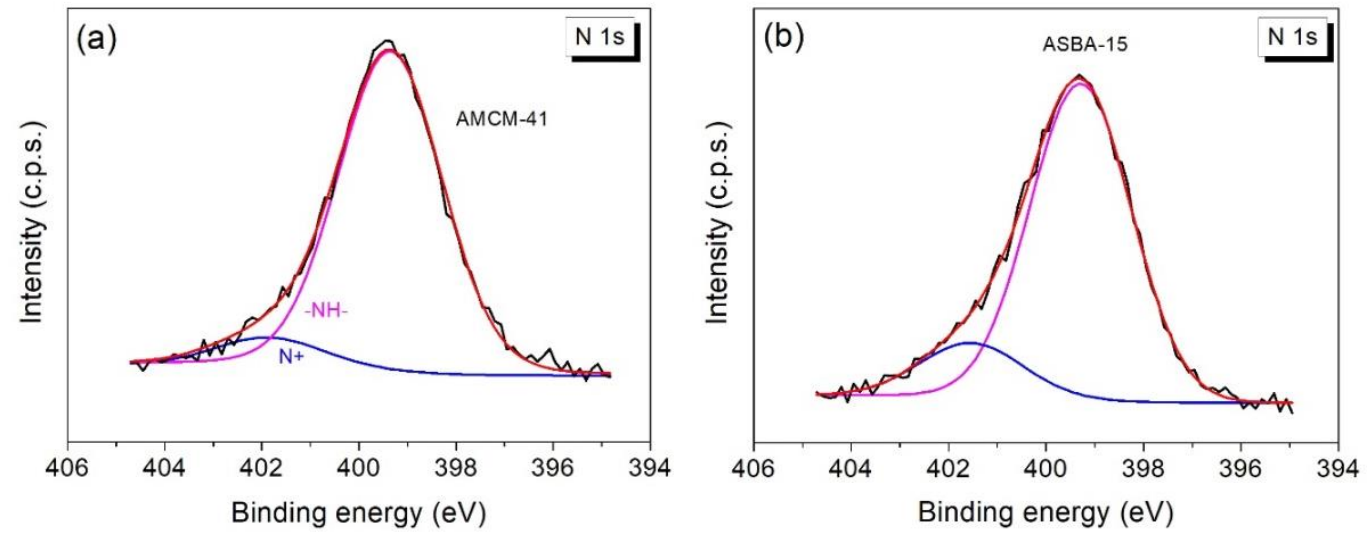

Figure 5: XPS spectrum of N $1 s$ for samples (a) AMCM-41 and (b) ASBA-15.

\section{2. $\mathrm{CO}_{2}$ Adsorption}

To evaluate the potential of the obtained materials as adsorbents for $\mathrm{CO}_{2}$ capture, Figure 6 shows the curves of carbon dioxide adsorption onto the developed materials. The MCM-41 and SBA-15 samples present low adsorption capacity for $\mathrm{CO}_{2}$ compared to materials functionalized with APTES. The adsorption capacity of $\mathrm{CO}_{2}$ increases despite the evident decrease in the specific surface area upon surface modification. This improved sorption capacity results from an enhancement in the surface affinity of the material with the adsorbent resulting from the incorporation of amino groups.

The observed enhancement of $\mathrm{CO}_{2}$ adsorption capacities on ASBA-15 and AMCM-41 is from 0.6 and $0.1 \mathrm{mmol} \cdot \mathrm{g}^{-1}$ to 1.8 and $1.0 \mathrm{mmol} \cdot \mathrm{g}^{-1}$, respectively. These adsorption improvements show the influence of amino groups in the structure of the mesoporous materials, favoring the adsorption process. Besides, these adsorption capacities were higher than those reported in similar studies using mesoporous silica materials $[33,34]$. Another relevant factor is that the adsorption process was conducted at atmospheric pressure (1 atm) and room temperature $\left(30^{\circ} \mathrm{C}\right)$, with a variation in adsorption time from 0 to $210 \mathrm{~min}$. These conditions can be adjusted to tune the adsorption capacities since changes in the adsorption temperature or pressure affect the amount uptake [35]. Note that the SBA-15 material shows a higher $\mathrm{CO}_{2}$ uptake than $\mathrm{MCM}-41$, even though its specific surface area is lower than the latter. This phenomenon occurs because of the intrinsic microporosity of the SBA-15 [36]. The positive effect of the microporosity on the $\mathrm{CO}_{2}$ uptake is welldocumented elsewhere $[37,38]$. Nonetheless, the adsorption capacity of SBA-15 is negligible when compared with the amino-functionalized material. 


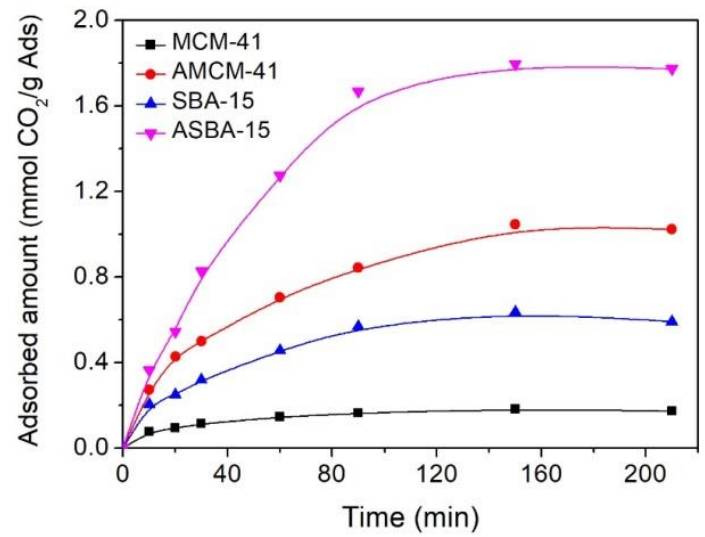

Figure 6: $\mathrm{CO}_{2}$ adsorption capacities of the obtained materials obtained at room temperature.

It is worthwhile to note that the $\mathrm{CO}_{2}$ adsorption capacity of the ASBA-15 $\left(1.8 \mathrm{mmol} \cdot \mathrm{g}^{-1}\right)$ tested at room temperature is high and is compatible with the sorption outcomes obtained using some chemically modified mesoporous materials already reported tested at similar or even higher temperatures. Briefly, $\mathrm{CO}_{2}$ adsorption of ca. $1.6 \mathrm{mmol} \mathrm{g}$-1 was reported for MCM-48 containing ethylenediamine (EDA) at $25{ }^{\circ} \mathrm{C}$ and using $400 \mathrm{mg}$ of the sample [39]. A series of hexagonal mesoporous silica (HMS) modified with polyethyleneimine (PEI) with different mesoporosities were used as materials for $\mathrm{CO}_{2}$ adsorption. A sample containing 60 wt.\% PEI loaded presented a $\mathrm{CO}_{2}$ sorption capacity of $4 \mathrm{mmol} \cdot \mathrm{g}^{-1}$ sorbent $\left(184 \mathrm{mg} \mathrm{g}^{-1}\right)$ at $75^{\circ} \mathrm{C}$ [40].

Likewise, the $\mathrm{CO}_{2}$ adsorption capacity of different functionalized mesoporous silicas of the SBA-15 type was investigated, and the influence of the textural properties and the effect of the silicon source on the $\mathrm{CO}_{2}$ uptake was studied. The most promising result was taken at the 1,3,5-triisopropylbenzene-fluoride impregnated with PEI (TiPB-F/50PEI silica), which captured $1.87 \mathrm{mmol} \mathrm{g}^{-1}$ and $2.21 \mathrm{mmol} \mathrm{g}^{-1}$ of $\mathrm{CO}_{2}$ at $25^{\circ} \mathrm{C}$ and $75^{\circ} \mathrm{C}$ in 1 bar [41].

\subsection{Kinetic Study}

From the results of $\mathrm{CO}_{2}$ adsorption over time, curves were constructed representing the kinetics of sorption of $\mathrm{CO}_{2}$ by the mesoporous materials. The data were fitted to the kinetic models of pseudo-first-order, $\log \left(\boldsymbol{q}_{e^{-}}\right.$ $\boldsymbol{q}_{t}$ ) versus time, and pseudo-second-order, $\mathrm{t} / \mathrm{q}_{\mathrm{t}}$ versus time. A proper correlation was found for the latter model, which is shown in Figure 7. The former did not fit well with the experimental data. Table 3 shows the kinetic parameters obtained from the linear regressions shown in Figure 7.

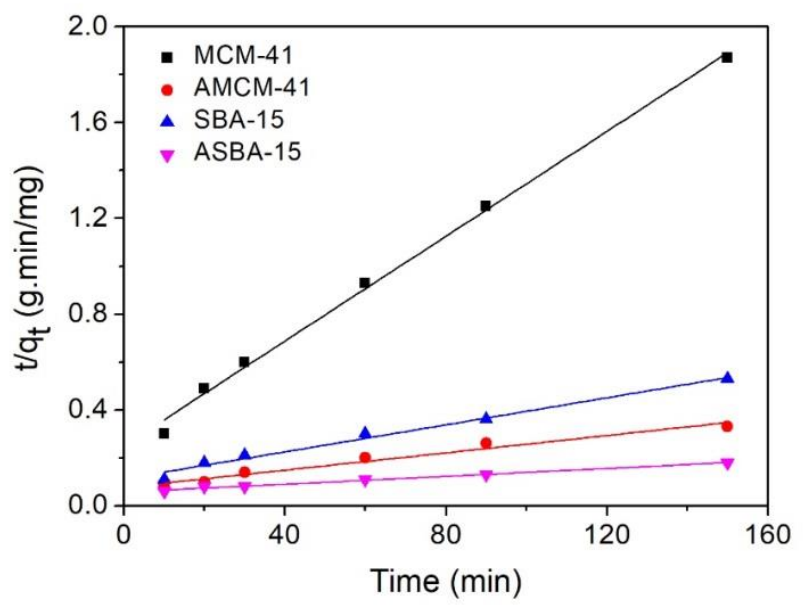

Figure 7: Kinetic analysis of the $\mathrm{CO}_{2}$ adsorption of materials studied at room temperature by a pseudo-second-order (PSO) equation. 
Quantitative evaluation of these models requires the comparison of the correlation coefficients $\left(\boldsymbol{R}^{2}\right)$. Notably, the $\boldsymbol{R}^{2}$ values calculated for the pseudo-second-order kinetic model are higher than 0.99. Another relevant parameter was the calculated $\boldsymbol{q}_{\boldsymbol{e}}$ values. Since the calculated values of $\boldsymbol{q}_{\boldsymbol{e}}$ are higher than the experimental values of $\boldsymbol{q}_{e}$, this one shows the consistency of the results; otherwise, if the calculated values of $\boldsymbol{q}_{e}$ are lower than the experimental values, they are irrelevant.

The $\mathrm{CO}_{2}$ adsorption experiments were very well fitted with the pseudo-second-order since this adjustment was confirmed by comparing the experimental $q_{e}$ values with the calculated ones, presenting good agreement. Bacsik and coworkers [42] studied the mechanisms and kinetics of sorption of $\mathrm{CO}_{2}$ on mesoporous silica modified with n-propylamine. From infrared spectroscopy data, they identified molecular species formed during the sorption of carbon dioxide on amine-modified MCM-48 and showed that the amine group reacts with $\mathrm{CO}_{2}$ to form ammonium carbamate ion pairs and carbamic acids, and it is one crucial reaction step for $\mathrm{CO}_{2}$ capture.

Table 3: Kinetic parameters of the $\mathrm{CO}_{2}$ adsorption onto the developed materials studied by Lagergren pseudo-secondorder equation.

\begin{tabular}{c|c|c|c|c|c}
\hline KINETIC MODEL & & MCM-41 & SBA-15 & AMCM-41 & ASBA-15 \\
\hline \multirow{5}{*}{ Second-order* } & $\mathrm{K}_{2}$ & $6.2 \times 10^{-3}$ & $1.1 \times 10^{-3}$ & $6.2 \times 10^{-4}$ & $2.8 \times 10^{-4}$ \\
& $\mathrm{R}^{2}$ & 0.99 & 0.99 & 0.99 & 0.99 \\
& $\mathrm{a}$ & 2.493 & 1.123 & 0.761 & 0.562 \\
& $\mathrm{~b}$ & 0.109 & 0.028 & 0.017 & 0.008 \\
& $\boldsymbol{q}_{e}$ experimental & 8 & 28 & 46 & 79 \\
& $\boldsymbol{q}_{e}$ calculated & 9 & 35 & 56 & 118 \\
\hline
\end{tabular}

\section{CONCLUSIONS}

Amino silanes-functionalized mesoporous molecular sieves (MCM-41 and SBA-15) were prepared by postsynthesis functionalization via a straightforward reflux method. Through physicochemical characterizations of the synthesized materials before and after modification with the amine, it was possible to evaluate the efficiency of the functionalization method, showing the presence of amino groups in the structure of mesoporous molecular sieves according to the XPS analyses. The $\mathrm{CO}_{2}$ adsorption increased on both samples containing amine, reaching $1.1 \mathrm{mmol} \cdot \mathrm{g}^{-1}$ for sample AMCM-41 and $1.8 \mathrm{mmol} \cdot \mathrm{g}^{-1}$ for sample ASBA-15. It was possible to compare the quantities adsorbed experimentally and theoretically through kinetic studies, thereby validating the adsorption experiments. The kinetic parameters obtained were best fitted to the kinetic model of second-order since the calculated values of $\boldsymbol{q}_{e}$ were consistent compared with the experimental values. The correction factor was equal to 0.99 . It is important to note that the $\mathrm{CO}_{2}$ adsorption process was carried out at room temperature under atmospheric pressure. The results are relevant for such materials, and their efficiency can be improved by varying the adsorption conditions at different pressures or temperatures.

\section{ACKNOWLEDGMENTS}

The authors thank the Brazilian Agency of Petroleum, Natural Gas and Biofuels (ANP), the National Council for Scientific and Technological Development (CNPq), Brazil (Grants: 306780/2018-6 and 305438/2018-2), CAPES (Grant: 001) and Ministerio de Ciencia, Innovación y Universidades, project RTI2018-099668BC22 and European FEDER funds for financial support. This work is a result of Brazil-Spain research cooperation.

\section{BIBLIOGRAPHY}

[1] CORFEE-MORLOJ, J., HÖHNE, N., "Climate change: long-term targets and short-term commitments", Global Environmental Change, v. 13, pp. 277-293, 2003. 
[2] AZARKAMAND, S., WOOLDRIDGE, C., DARBRA, R.M., "Review of Initiatives and Methodologies to Reduce CO2 Emissions and Climate Change Effects in Ports", International Journal of Environmental Research and Public Health, v. 17, pp. 3858, 2020.

[3] KAMRAN, U., PARK, S.-J., "Chemically modified carbonaceous adsorbents for enhanced $\mathrm{CO}_{2}$ capture: A review", Journal of Cleaner Production, v. 290, pp. 125776, 2021.

[4] DU, R., FENG, X., CHAKMA, A., "Poly(N,N-dimethylaminoethyl methacrylate)/polysulfone composite membranes for gas separations", Journal Membrane Science, v. 279, pp. 76-85, 2006.

[5] TAJNIK, T., BOGATAJ, L.K., JURAC, E., et al., "Investigation of adsorption properties of geological materials for $\mathrm{CO}_{2}$ storage", International Journal Energy Research, v. 37, pp. 952-958, 2013.

[6] YU, C., HUANG, C., TAN, C., "A Review of $\mathrm{CO}_{2}$ Capture by Absorption and Adsorption”, Aerosol Air Quality Research, v. 12, pp. 745-769, 2012.

[7] ÜNVEREN, E.E., MONKUL, B.O., SARIOGLAN, S., et al., "Solid amine sorbents for $\mathrm{CO}_{2}$ capture by chemical adsorption: A review", Petroleum, v. 3, pp. 37-50, 2017.

[8] CARVALHO, L.S., SILVA, E., ANDRADE, J.C., et al., "Low-cost mesoporous adsorbents aminesimpregnated for $\mathrm{CO}_{2}$ capture", Adsorption, v. 21, pp. 597-609, 2015.

[9] VILARRASA-GARCÍA, E., CECILIA, J.A., BASTOS-NETO, M., et al., " $\mathrm{CO}_{2} / \mathrm{CH}_{4}$ adsorption separation process using pore expanded mesoporous silicas functionalizated by APTES grafting", Adsorption, v. 21, pp. 565-575, 2015.

[10] MONTAgnaro, F., Silvestre-Albero, A., RODRIGUEZ-REINOSO, F., et al., "Postcombustion $\mathrm{CO}_{2}$ adsorption on activated carbons with different textural properties", Microporous Mesoporous Materials, v. 209, pp. 157-164, 2015.

[11] OJEDA-LÓPEZ, R., DOMÍNGUEZ-ORTIZ, A., FELIPE, C., et al., "Isosteric enthalpy behavior of $\mathrm{CO}_{2}$ adsorption on micro-mesoporous materials: carbon microfibers (CMFs), SBA-15, and amine-functionalized SBA-15" Journal of Composites Science, v. 5, pp. 102, 2021.

[12] BALARAMAN, E., GUNATHAN, C., ZHANG. J., et al., "Efficient hydrogenation of organic carbonates, carbamates and formates indicates alternative routes to methanol based on $\mathrm{CO}_{2}$ and $\mathrm{CO}$ ", Nature Chemistry, v. 3, 609-614, 2011.

[13] HORI, K., HIGUCHI, T., AOKI, Y., et al., "Effect of pore size, aminosilane density and aminosilane molecular length on $\mathrm{CO}_{2}$ adsorption performance in aminosilane modified mesoporous silica", Microporous and Mesoporous Materials, v. 246, pp. 158-165, 2017.

[14] RIBEIRO, J.D.N., NUNES, E.H.M., VASCONCELOS, D.C.L., et al., "Role of the type of grafting solvent and its removal process on APTES functionalization onto SBA-15 silica for $\mathrm{CO}_{2}$ adsorption", Journal of Porous Materials, v. 26, pp. 1581-1591, 2019.

[15] MADDEN, D.G., DANIELS, E.A., HANRAHAN, J.P. et al., "Pseudomorphic transformation and post synthetic modification of amorphous silica for $\mathrm{CO}_{2}$ sorption applications", SN Applied Sciences, v. 1, pp. 996, 2019.

[16] SANZ, R., CALLEJA, G., ARENCIBIA, A., et al., " $\mathrm{CO}_{2}$ capture with pore-expanded MCM-41 silica modified with amino groups by double functionalization", Microporous and Mesoporous Materials., v. 209, pp. 165-171, 2015.

[17] ARAUJO, A.S., JARONIEC, M., "Thermogravimetric monitoring of the MCM-41 synthesis", Thermochimica Acta, v. 363, pp. 175-180, 2000.

[18] ZHAO, D., HUO, Q., FENG, J., et al., "Nonionic Triblock and Star Diblock Copolymer and Oligomeric Surfactant Syntheses of Highly Ordered, Hydrothermally Stable, Mesoporous Silica Structures", Journal of the American Chemical Society, v. 120, pp. 6024-6036, 1998.

[19] QIANG, Z., GUO, Y., LIU, H., et al., "Large-Scale Roll-to-Roll fabrication of ordered mesoporous materials using resol-assisted cooperative assembly", Applied Materials Interfaces, v. 7, pp. 4306-4310, 2015.

[20] QIANG, Z., GURKAN, B., MA, J., et al., "Roll-to-roll fabrication of high surface area mesoporous carbon with process-tunable pore texture for optimization of adsorption capacity of bulky organic dyes, $\mathrm{Mi}$ croporous and Mesoporous Materials, v. 227, pp. 57-64, 2016. 
[21] JARONIEC, M., SOLOVYOV, L.A., "Improvement of the Kruk-Jaroniec-Sayari method for pore size analysis of ordered silicas with cylindrical mesopores", Langmuir, v. 22, pp. 6757-6760, 2006.

[22] AYYAPPAN, R., SOPHIA, A.C., SWAMINATHAN, K., et al., "Removal of Pb(II) from aqueous solution using carbon derived from agricultural wastes", Process Biochemistry, v. 40, pp. 1293-1299, 2005.

[23] YUH-SHAN, H. "Citation review of Lagergren kinetic rate equation on adsorption reactions", Scientometrics, v. 59, pp. 171-177, 2004.

[24] HO, Y.S., McKAY, G., "Batch Lead(II) Removal From Aqueous Solution by Peat: Equilibrium and Kinetics”, Process Safety Environmental Protection, v. 77, pp.165-173, 1999.

[25] BECK, J.B., VARTULI, J.C., ROTH, W.J., et al., "A new family of mesoporous molecular sieves prepared with liquid crystal templates", Journal of the American Chemical Society, v. 114, pp. 10834-10843, 1992.

[26] KRESGE, C.T., LEONOWICS, M.E., ROTH, W.T., et al., "Ordered mesoporous molecular sieves synthesized by a liquid-crystal template mechanism", Nature, v. 359, 710-712, 1992.

[27] ZHAO, D., HUO, Q., FENG, J., et al., "Nonionic triblock and star diblock copolymer and oligomeric sufactant syntheses of highly ordered, hydrothermally stable, mesoporous silica structures, Journal of the American Chemical Society, v. 120, pp. 6024-6036, 1998.

[28] ZHAO, D.Y., FENG, J.L., HUO, Q.S., et al., "Triblock copolymer syntheses of mesoporous silica with periodic 50 to 300 angstrom pores", Science, v. 279, pp. 548-552, 1998.

[29] THOMMES, M., KANEKO, K., NEIMARK, A.V., et al., "Physisorption of gases, with special reference to the evaluation of surface area and pore size distribution" (IUPAC Technical Report), Pure Appl. Chem., v. 87, pp. 1051-1069, 2015.

[30] CHAREONPANICH, M., NANGERN, A., LIMTRAKUL, J., et al., "Short-period synthesis of ordered mesoporous silica SBA-15 using ultrasonic technique", Materials Letters, v. 61, pp. 5153-5156, 2007.

[31] VILLAROEL-ROCHA, J., BARRERA, D., SAPAG, K., "Introducing a self-consistent test and the corresponding modification in the Barrett, Joyner and Halenda method for pore-size determination", Microporous and Mesoporous Materials, v. 200, pp. 68-78, 2014.

[32] COSTA, M.J.F., CORIOLANO, A.C.F., SILVA, C.G.C., et al., "Development of HZSM-5/AIMCM-41 hybrid micro-mesoporous material and application for pyrolysis of vacuum gasoil", Microporous and Mesoporous Materials, v. 172, pp. 206-212, 2013.

[33] MA, X., WANG, X., SONG, C., "Molecular Basket" Sorbents for Separation of $\mathrm{CO}_{2}$ and $\mathrm{H} 2 \mathrm{~S}$ from Various Gas Streams", Journal of the American Chemical Society, v. 131, pp. 5777-5783, 2009.

[34] XU, X., SONG, C., ANDRÉSEN, J.M., et al., "Preparation and characterization of novel $\mathrm{CO}_{2}$ " $m o l e c u-$ lar basket" adsorbents based on polymer-modified mesoporous molecular sieve MCM-41", Microporous and Mesoporous Materials, v. 62, pp. 29-45, 2003.

[35] SANZ-PÉREZ, E.S., DANTAS, T.C.M., ARENCIBIA, A., et al., "Reuse and recycling of aminefunctionalized silica materials for $\mathrm{CO}_{2}$ adsorption", Chemical Engineering Journal, v. 308, pp. 1021-1033, 2017.

[36] KRUK, M., JARONIEC, M., KO, C.H., et al., "Characterization of the Porous Structure of SBA-15", Chemical Materials., v. 12, pp. 1961-1968, 2000.

[37] LUDWINOWICS, J., JARONIEC, M., "Effect of activating agents on the development of microporosity in polymeric-based carbon for $\mathrm{CO}_{2}$ adsorption", Carbon, v. 94, pp. 673-679, 2015.

[38] LIU Y., LIU, S., GONCALVEZ, A.A.S., et al., "Effect of metal-ligand ratio on the $\mathrm{CO}_{2}$ adsorption properties of Cu-BTC metal-organic frameworks", RSC Advances, v. 8, pp. 35551-35556, 2018.

[39] OLIVEIRA, T.G., SOUZA, M.J.B., CORIOLANO, A.C.F., " $\mathrm{CO}_{2}$ adsorption on systems involving ethylenediamine impregnated on nanoporous materials", Petroleum Science Technology, v. 36, pp. 1977-1982, 2018.

[40] CHAO, C., WON-JIN, S., KWANG-SEOK, Y., et al., "Carbon dioxide capture using amineimpregnated HMS having textural mesoporosity", Chemical Engineering Journal, v. 161, pp. 46-52, 2010. 
[41] VILARRASA-GARCÍA, E., CECILIA, J.A., MOYA, E.M.O., et al., "Low cost" pore expanded SBA15 functionalized with amine groups applied to $\mathrm{CO}_{2}$ adsorption", Adsorption Materials, v. 8(5), pp. 24952513, 2015.

[42] BACSIK, Z., AHLSTEN, N., ZIADI, A., et al., "Mechanisms and Kinetics for Sorption of $\mathrm{CO}_{2}$ on Bicontinuous Mesoporous Silica Modified with n-Propylamine”, Langmuir, v. 27, 11118-11128., 2011.

\section{ORCID}

Giancarlo Richard Salazar Banda

Maricele Nascimento Barbosa

Marcela Nascimento Barbosa

Maria José Fonseca Costa

Álvaro Reyes-Carmona

Enrique Rodríguez-Castellón

Antonio Souza Araujo

Valter José Fernandes Júnior https://orcid.org/0000-0002-3252-1746

http://orcid.org/0000-0002-2211-5357

https://orcid.org/0000-0002-2651-497X

https://orcid.org/0000-0002-4170-4851

https://orcid.org/0000-0002-2860-571X

https://orcid.org/0000-0003-4751-1767

http://orcid.org/0000-0002-1223-2939

http://orcid.org/0000-0001-6549-0643 